\title{
Anti-cariogenic Characteristics of Rubusoside
}

\author{
Jeesoo Kim, Thi Thanh Hanh Nguyen, Juhui Jin, Iis Septiana, Gyu-Min Son, Gang-Hee Lee, You-Jin Jung, \\ Dilshad Qureshi, Il Kyoon Mok, Kunal Pal, Soo-Yeon Yang, Seong-Bo Kim, and Doman Kim
}

Received: 17 October 2018 / Revised: 28 November 2018 / Accepted: 18 December 2018

(C) The Korean Society for Biotechnology and Bioengineering and Springer 2019

\begin{abstract}
Streptococcus mutans plays an important role in the development of dental caries in humans by synthesizing adhesive insoluble glucans from sucrose by mutansucrase activity. To explore the anti-cariogenic characteristics of rubusoside $(\mathrm{Ru})$, a natural sweetener component in Rubus suavissimus S. Lee (Rosaceae), we investigated the inhibitory effect of $\mathrm{Ru}$ against the activity of mutansucrase and the growth of Streptococcus mutans. Ru $(50 \mathrm{mM})$ showed $97 \%$ inhibitory activity against $0.1 \mathrm{U} / \mathrm{mL}$ mutansucrase of S. mutans with $500 \mathrm{mM}$ sucrose. It showed competitive inhibition with a $K_{i}$ value of $1.1 \pm 0.2 \mathrm{mM}$ and $\mathrm{IC}_{50}$ of $2.3 \mathrm{mM}$. Its inhibition activity was due to hydrophobic and hydrogen bonding interactions based on molecular docking analysis. $\mathrm{Ru}$ inhibited the growth of $S$. mutans as a bacteriostatic agent, with MIC and MBC values of $6 \mathrm{mM}$ and $8 \mathrm{mM}$, respectively. In addition, Ru showed synergistic anti-bacterial activity when it was combined with curcumin. Therefore, $\mathrm{Ru}$ is a natural anti-cariogenic agent with antimutansucrase activity and antimicrobial activity against S. mutans.
\end{abstract}

Jeesoo Kim ${ }^{\dagger}$, Thi Thanh Hanh Nguyen ${ }^{\dagger}$, Juhui Jin, Iis Septiana, Gyu-Min Son, Gang-Hee Lee, You-Jin Jung, Il Kyoon Mok, Soo-Yeon Yang, Doman Kim*

Graduate School of International Agricultural Technology and Institutes of Green Bioscience \& Technology, Seoul National University, Pyeongchang 25354, Korea

Tel: +82-33-339-5720; Fax: +82-33-339-5716

E-mail:kimdm@snu.ac.kr

Dilshad Qureshi, Kunal Pal

Department of Biotechnology and Medical Engineering, National Institute of Technology, Rourkela, India

Seong-Bo Kim

CJ CheilJedang, Life Ingredient \& Material Research Institute, Suwon 16495, Korea

'The first two authors contributed equally to this work.
Keywords: Anti-cariogenicity, mutansucrase, natural sweetener, rubusoside, Streptococcus mutans

\section{Introduction}

Dental caries affects $80 \%$ of the world's population. It is costly to health care. Dental caries is initiated by interaction between acidogenic bacteria and sucrose in susceptible hosts. Streptococcus mutans is an acidogenic and acidtolerant bacterial species. It has been recognized as the primary pathogen of dental caries because of its ability to produce glucansucrase synthesizing water insoluble glucan called mutan [1]. Mutan can mediate the adherence of S. mutans and other oral bacterial species to tooth surfaces, contributing to the formation of dental plaque biofilms [2,3]. Glucansucrases are a member of glycoside hydrolase (GH) family 70 that catalyze the formation of glucan with various types of glucosidic linkages such as $\alpha(1-3), \alpha(1-4)$, or $\alpha(1-6)$ bonds, from sucrose via transglucosylation reactions. Glucansucrases are classified at mutansucrase, dextransucrase, alternansucrase, and reuternansucrase, which catalyzed $\alpha(1-3), \alpha(1-6), \alpha(1-3$ and 1-6), and $\alpha(1-4$ and 1-6) bond formation, respectively [4]. S. mutans produces three extracellular glycosyltransferases (GTFs), GTF-I, GTF-SI and GTF-S, which are encoded by $g t f$ B, $g t f \mathrm{C}$, and $g t f \mathrm{D}$, respectively. GTF-I and GTF-SI are mutansucrases that synthesize mainly insoluble glucan with $\alpha(1-3)$ glucosidic linkages [5,6]. In addition, other crucial virulence factors of $S$. mutans include a membranebound F1Fo-ATPase system, agmatine deiminase system, enolase, and lactate dehydrogenase [7]. Diet, especially high sucrose intake, elevates the risk for dental caries. The cariogenic nature of sucrose has led food and beverage industries to develop alternative sweeteners without having carcinogenicity. 
Rubusoside (13-O- $\beta$-glucosyl-19-O- $\beta$-D-glucosyl-steviol; $\mathrm{Ru}$ ) is one of the steviol glycosides present in the leaves of Rubus suavissimus S. Lee (Rosaceae). It is a well-known natural nontoxic sweetening agent. It has been used in various food and beverage products [8]. In addition, Ru has been used to increase the solubility of several pharmaceutically and medically important compounds with poor solubility in water [9]. It can decrease the growth and glass-surface adherence of $S$. mutans [10] when $\mathrm{Ru}$ and sucrose are incubated together and then the growth, adherence, and acid production of $S$. mutans are measured. The mechanism involved in the inhibition of $\mathrm{Ru}$ against mutansucrase or its reduction of the growth of $S$. mutans is currently unknown. Therefore, the objective of this study was to investigate the mechanism of action of Ru against mutansucrase and $S$. mutans growth. Kinetic characterization of $\mathrm{Ru}$ against mutansucrase activity and molecular docking analysis were carried out. The growth inhibition type of $\mathrm{Ru}$ against $S$. mutans was also studied.

\section{Materials and Methods}

\subsection{Preparation of rubusoside}

$\mathrm{Ru}$ was prepared using stevioside as a substrate with immobilized $\beta$-galactosidase expressed in Escherichia coli BL21 (DE3) pLysS and was purified as described in our previous study [9].

\subsection{Preparation of mutansucrase from $S$. mutans} S. mutans KCTC 3065 was obtained from Korean Collection for Type Cultures (KCTC, Korea). Mutansucrase was prepared by culturing $S$. mutans in brain heart infusion media (BHI; BD Difco, USA) supplemented with $2 \%(\mathrm{w} / \mathrm{v})$ glucose at $37^{\circ} \mathrm{C}$ with shaking (at $150 \mathrm{rpm}$ ) until all glucose was consumed. After fermentation, cells were separated from the broth by centrifugation at $8,000 \times \mathrm{g}$ for $15 \mathrm{~min}$. The supernatant was concentrated using a Centriprep Centrifugal Filter Unit with Ultracel-YM10 (Merck, Germany) and loaded onto a DEAE-Sepharose ion-exchange chromatography column $(1 \times 1 \times 60 \mathrm{~cm})$ equilibrated with $20 \mathrm{mM}$ sodium phosphate buffer $(\mathrm{pH}$ 6.8). Mutansucrase was eluted with a salt gradient of $0-1,000 \mathrm{mM} \mathrm{NaCl}$ in $20 \mathrm{mM}$ sodium phosphate buffer $(\mathrm{pH}$ 6.8). Fractions containing mutansucrase were pooled and dialyzed with $20 \mathrm{mM}$ sodium phosphate buffer $(\mathrm{pH} 6.8)$ at $4^{\circ} \mathrm{C}$. These dialyzed fractions were concentrated using a Centriprep Centrifugal Filter Unit with Ultracel-YM10 and analyzed by sodium dodecyl sulfate polyacrylamide gel electrophoresis (SDS-PAGE). Protein concentration was measured by the Bradford method using crystalline bovine serum as standard
[9]. The partially purified enzyme was kept at $-20^{\circ} \mathrm{C}$ for further study. One unit $(\mathrm{U})$ of mutansucrase activity was defined as the amount of enzyme required to release $1 \mu \mathrm{M}$ fructose from sucrose per min at $37^{\circ} \mathrm{C}$ and $\mathrm{pH}$ 6.8. Fructose concentration in the reaction mixture was measured with a D-fructose kit (Megazyme, Ireland). The kinetic parameter of mutansucrase activity $(0.1 \mathrm{U} / \mathrm{mL})$ was measured using 0-200 $\mathrm{mM}$ sucrose as the substrate for $35 \mathrm{~min}$. Reaction responses were linear within this time frame. The MichalisMenten constant $\left(K_{m}\right)$ was calculated from LineweaverBurk plot [11].

\subsection{Inhibition activity of rubusoside against mutansucrase} $\mathrm{Ru}$ was dissolved in distilled water to prepare a $250 \mathrm{mM}$ stock solution. The reaction mixture was composed of $0.1 \mathrm{U} / \mathrm{mL}$ mutansucrase, $500 \mathrm{mM}$ sucrose, and $50 \mathrm{mM} \mathrm{Ru}$ in $20 \mathrm{mM}$ sodium phosphate buffer $(p \mathrm{H}$ 6.8). After incubating at $37^{\circ} \mathrm{C}$ for $12 \mathrm{~h}$, water-insoluble glucan was harvested by centrifugation at $12,000 \times \mathrm{g}$ for $15 \mathrm{~min}$. The pellet was dissolved in $1 \mathrm{M} \mathrm{NaOH}$. The amount of waterinsoluble glucan was measured via thin-layer chromatography (TLC) [12]. One $\mu \mathrm{l}$ of sample was spotted onto a precoated TLC plate (Merck, Darmstadt, Germany) and developed with two ascents of acetonitrile:water (85:15, v/v). Carbohydrates were visualized by dipping the TLC plate into $0.5 \%$ (w/v) $N$-(1-naphtyl) ethylenediamine dihydrochloride (Sigma Aldrich, USA) and 5\% (w/v) sulfuric acid (Duksan Chemicals, South Korea) in methanol (Duksan Chemicals, South Korea) followed by heating at $120^{\circ} \mathrm{C}$ for $5 \mathrm{~min}$. The amount of carbohydrates was analyzed by conversion to the integrated density value using the AlphaEaseFC 4.0 Image Program (Alpha Inotech, CA, USA) [12].

The $50 \%$ inhibitory concentration $\left(\mathrm{IC}_{50}\right)$ was defined as the concentration of Ru necessary to reduce mutansucrase activity by $50 \%$ relative to a reaction mixture containing mutansucrase without inhibitor. $\mathrm{IC}_{50}$ and $K_{i}$ value of $\mathrm{Ru}$ against mutansucrase were calculated based on the amount of fructose released into the reaction mixture using a fructose kit. Inhibition activity was calculated using the following formula:

Inhibition activity $(\%)=100-\left[\left(S-S_{0}\right) /\left(C-C_{0}\right)\right] \times 100$,

where $C$ was the absorbance of control (enzyme, buffer, and substrate) after $35 \mathrm{~min}$ of reaction, $C_{0}$ was the absorbance of control at the zero-time point, $S$ was the absorbance of the sample (enzyme, Ru, buffer, or substrate) after $35 \mathrm{~min}$ of reaction, and $S_{0}$ was the absorbance of sample at the zero-time point. Inhibitor kinetic studies of $\mathrm{Ru}$ were done like those used in a kinetic study for mutansucrase, except that multiple concentrations (0- 
$10 \mathrm{mM})$ of $\mathrm{Ru}$ and various concentrations $(35-175 \mathrm{mM}$ sucrose) of substrate were used. The type of inhibition was identified using a Lineweaver-Burk and Dixon plot (1/v) as a function of inhibition concentration [I]. The kinetic parameter $\left(K_{i}\right)$ was calculated using the SigmaPlot program.

2.4. Antibacterial effect assay by disc diffusion method S. mutans was cultured in brain-heart infusion (BHI) at $37^{\circ} \mathrm{C}$ until $\mathrm{OD}_{600}$ reached approximately $1.0[13,14]$. The antibacterial effect of $\mathrm{Ru}$ solution $(250 \mathrm{mM})$ against S. mutans was measured using epigallocatechin gallate (EGCG) $(250 \mathrm{mM})$ as a control [15]. Both the Ru solution and EGCG $(250 \mathrm{mM})$ were filtered with a Minisart ${ }^{\circledR}$ syringe filter $(0.2 \mu \mathrm{m}$, Satorius, Germany). A disc-diffusion antimicrobial test was carried out by spreading $100 \mu \mathrm{L}$ of suspension containing $10^{8} \mathrm{CFU} / \mathrm{mL}$ onto a BHI agar plate [15]. Then a $6-\mathrm{mm}$ diameter disc containing $20 \mu \mathrm{L}$ of $250 \mathrm{mM} \mathrm{Ru}, 250 \mathrm{mM}$ EGCG, or dimethyl sulfoxide (DMSO) was processed in triplicate. These discs were impregnated into the inoculated agar plate. These plates were then incubated at $37^{\circ} \mathrm{C}$ for $12 \mathrm{~h}$.

\subsection{Molecular docking of Ru against mutansucrase} The three-dimensional structure of mutansucrase was retrieved from the Protein Data Bank (http://www.rcsb.org, accession code 3AIC). Alpha acrabose (ACR) is located in the active site of 3AIC [6]. All water molecules and cocrystal ligand ACR were removed. Structure information containing only amino-acid residues of mutansucrase enzyme was used for molecular docking. All docking experiments were carried out according to the previous published method [16].

2.6. Minimum inhibition concentration (MIC) and minimum bactericidal concentration (MBC) against S. mutans

Curcumin was purchased from Sigma. Water-soluble curcumin (Ru-CUR) was prepared as described previously [9]. A broth microdilution method was used to find the minimum inhibitory concentration (MIC) and minimum bacterial concentration (MBC) [17]. To measure MIC, Ru or Ru-CUR was placed into each well of a 96-well-plate. Each well was then inoculated with $5 \mu \mathrm{L}$ of $S$. mutans culture $\left(1.5 \times 10^{7} \mathrm{CFU} / \mathrm{mL}\right)$ and incubated at $37^{\circ} \mathrm{C}$ for $24 \mathrm{~h}$. Thereafter, turbidity of each well was measured with a SpectraMax M3 (Molecular devices, USA) at a wavelength of $600 \mathrm{~nm}$. The lowest concentration that inhibited bacterial growth was considered to be the MIC. MBC was measured by subculturing the medium from $\mathrm{MIC}$ on a $\mathrm{BHI}$ agar plate. These plates were incubated at $37^{\circ} \mathrm{C}$ for $24 \mathrm{~h}$. MBC was defined as the consequent concentration that killed
$99.9 \%$ of cells. All experiments were carried out in triplicate.

\section{Results and Discussion}

\subsection{Characterization of mutansucrase from $\boldsymbol{S}$. mutans}

Mutansucrase from Streptococcus mutans was purified using DEAE-Sepharose column (Fig. S1). The specific activity of mutansucrase after purification was $14.4 \mathrm{U} / \mathrm{mg}$ protein when using sucrose as a substrate. The Michaelis-Menten constant $\left(K_{m}\right)$ of mutansucrase using sucrose as a substrate was $34.5 \pm 4.6 \mathrm{mM}$ (Fig. S2) based on the amount of fructose released in the reaction mixture. The $K_{m}$ value of mutansucrase in this study was higher than that of mutansucrase from $S$. mutans Ingbritt c $\left(K_{m}=9.4 \mathrm{mM}\right)$ [18] and that of $S$. mutans $6715\left(K_{m}=2.4 \mathrm{mM}\right)[19]$. The $\mathrm{K}_{\mathrm{m}}$ values of $S$. mutans Ingbritt c and 6715 were determined by the phenol sulfuric acid assay, which measured measuring the total glucan formation in the reaction mixture containing sucrose and dextran T10 [19].

\subsection{Inhibition activity of rubusoside against mutansucrase} $\mathrm{Ru}$ was tested for its ability to inhibit mutansucrase. At $50 \mathrm{mM}$, Ru showed $97 \%$ inhibition against mutansucrase (Fig. 1A) based on insoluble glucan formation. The $\mathrm{IC}_{50}$ value of $\mathrm{Ru}$ against mutansucrase was $2.3 \mathrm{mM}$. Based on both Lineweaver-Burk and Dixon plots, $\mathrm{Ru}$ exhibited competitive inhibition toward mutansucrase, because the Lineweaver-Burk plot of $1 / \mathrm{v}$ versus $1 /[\mathrm{S}]$ resulted in a family of straight lines with the same $y$-axis intercept (Fig. 1B). The $K_{i}$ value of Ru was found to be $1.1 \pm 0.2 \mathrm{mM}$ (Fig. 1C). To our best knowledge, this is the first report about the inhibitory effect of Ru against mutansucrase.

\subsection{Molecular docking of Ru against mutansucrase}

To have a better comprehension of the molecular recognition process between mutansucrase and $\mathrm{Ru}$, docking experiments were done using the crystal structure of mutansucrase (3AIC) [6] and Autodock 4.2 for docking simulations. The free binding energy of Ru was $-8.27 \mathrm{kcal} / \mathrm{mol}$ (Fig. 2A). Ru inhibited mutansucrase from $S$. mutans potentially through hydrophobic and hydrogen bond (H-bond) interactions between amino-acid residues in the active site pocket of mutansucrase and $\mathrm{Ru}$ (Fig. 2B). Carbon atoms of $\mathrm{Ru}$ interacted hydrophobically with Leu 433, Leu434, Ala478, Asp480, Glu515, Trp517, and Tyr916. Ru formed three Hbonds with residues in the catalytic binding pocket of mutansucrase. The $\mathrm{O}^{7}$ atom of the 2-hydroxyl group of the glucosyl group at C19 of Ru accepted an H-bond with the amino group of Lys977 at a distance of $2.61 \AA$. The O atom of the side chain carboxyl group of Asp909 formed 
A

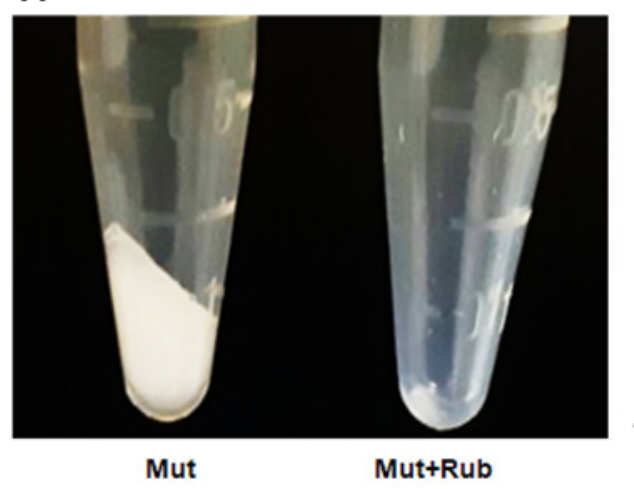

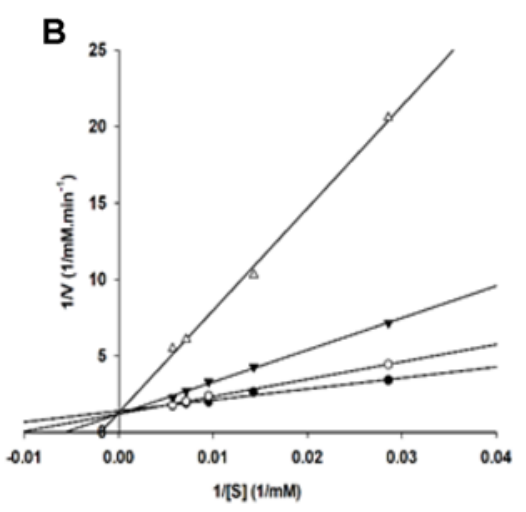

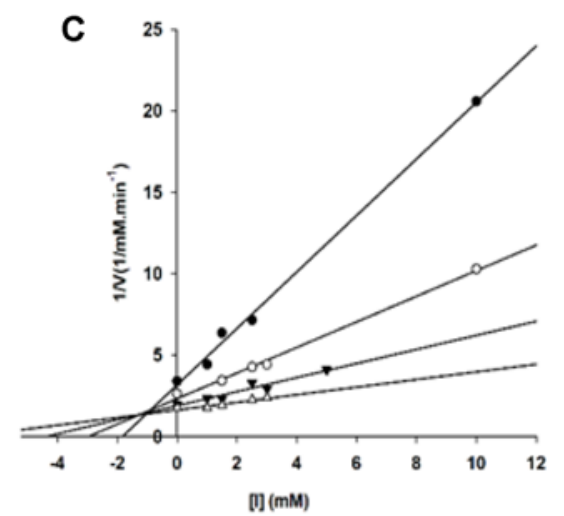

Fig. 1. Effect of $\mathrm{Ru}$ on reducing insoluble glucan formation using mutansucrase from $S$. mutans (A) and the plots of Lineweaver-Burk (B) and Dixon (C) analyzing Ru inhibition of mutansucrase activity. Kinetic constants $K_{m}$ and $K_{i}$ were calculated using linear regression analysis. In (A), Mut, mutansucrase reaction without $\mathrm{Ru}$ and $\mathrm{Mut}+\mathrm{Ru}$, mutansucrase reaction with $50 \mathrm{mM} \mathrm{Ru}$. The while color material indicates the formation of insoluble glucan. The mutansucrase reaction mixture comprised of $0.1 \mathrm{U} / \mathrm{mL}$ mutansucrase, $500 \mathrm{mM}$ sucrose, and $50 \mathrm{mM} \mathrm{Ru}$ in $20 \mathrm{mM}$ sodium phosphate buffer $\left(\mathrm{pH} \mathrm{6.8)}\right.$ ) and reacted at $37^{\circ} \mathrm{C}$ for $12 \mathrm{~h}$. The amount of water-insoluble glucan was determined using thin-layer chromatography (TLC). The amount of carbohydrates was analyzed by the AlphaEaseFC 4.0 Image Program which measures the integrated density value. In (B), the Ru concentration was $0 \mathrm{mM}(\mathbf{O}), 1 \mathrm{mM}(\bigcirc), 2.5 \mathrm{mM}(\bullet)$, and $10 \mathrm{mM}$ $(\Delta)$. In $(\mathrm{C})$, the sucrose substrate concentration was $35 \mathrm{mM}(\bullet), 70 \mathrm{mM}(\bigcirc), 10 \mathrm{mM}(\mathbf{\Delta})$, and $175 \mathrm{mM}$.

A

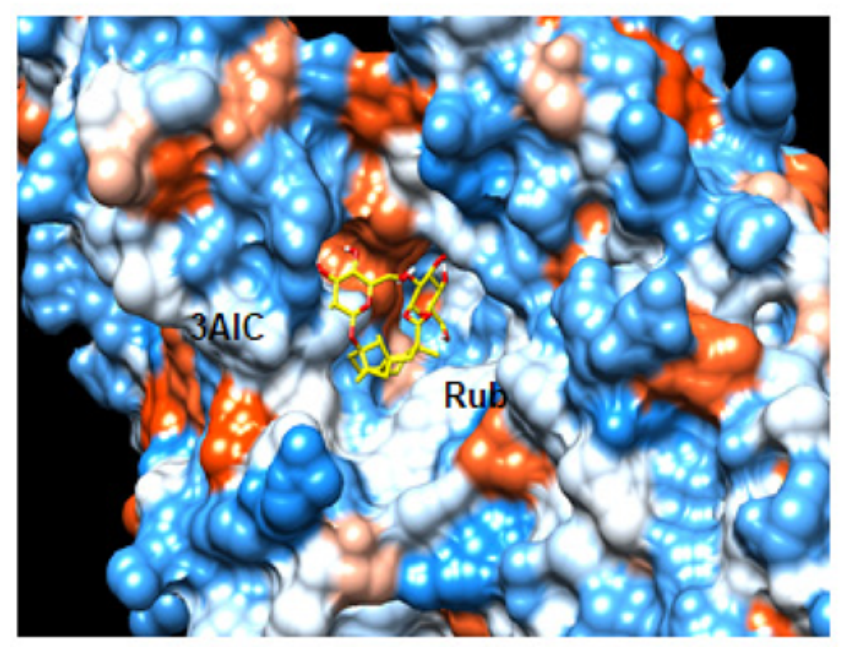

B

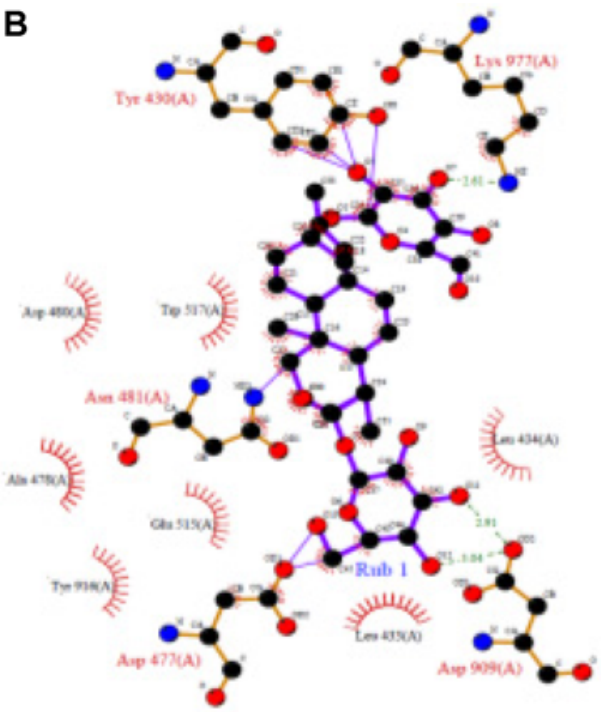

Fig. 2. Computation docking and hydrophobic and hydrogen bond interactions of $\mathrm{Ru}$ with amino-acid residues in the active site of mutansucrase. (A) Comparison of the binding mode of Ru (yellow) in the active site of mutansucrase. (B) Hydrophobic and H-bond interactions between Ru and amino-acid residues in the active site of mutansucrase. H-bond interactions are represented by green dashed lines (Red, oxygen; cornflower blue, nitrogen; black, carbon).

two H-bonds with $\mathrm{O} 11$ and $\mathrm{O} 12$ of the glucosyl group at $\mathrm{C} 13$ of Ru at a distance of $2.91 \AA$ and $3.04 \AA$, respectively.

\subsection{Antimicrobial susceptibility test of rubusoside and} rubusoside-curcumin complex against $S$. mutans growth The antimicrobial activities of Ru against $S$. mutans have been reported previously by $\mathrm{Chu}$ et al. (2016) after incubating Ru with $S$. mutans in the presence of sucrose. Our study confirmed the antibacterial activity of $\mathrm{Ru}$ by MIC and MBC studies. The antimicrobial activities of Ru against $S$. mutans growth were assessed by an inhibition zone assay and zone diameter measurement (Fig. S3). Ru inhibited the growth of $S$. mutans. The inhibition zone at $5 \mathrm{mM} /$ disc was $11.3 \pm 1 \mathrm{~mm}$. EGCG was used as a positive control. Its inhibition zone at $5 \mathrm{mM} /$ disc was $19 \pm 1 \mathrm{~mm}$. MIC and MBC values of Ru against $S$. mutans were $6 \mathrm{mM}$ and $8 \mathrm{mM}$, respectively (Fig. 3A). MBC was higher than MIC, indicating that $\mathrm{Ru}$ could inhibit $S$. mutans as a bacteriostatic agent [20]. Ru is known to be less acidogenic than is glucose, maltose, fructose, or sucrose, which can be 


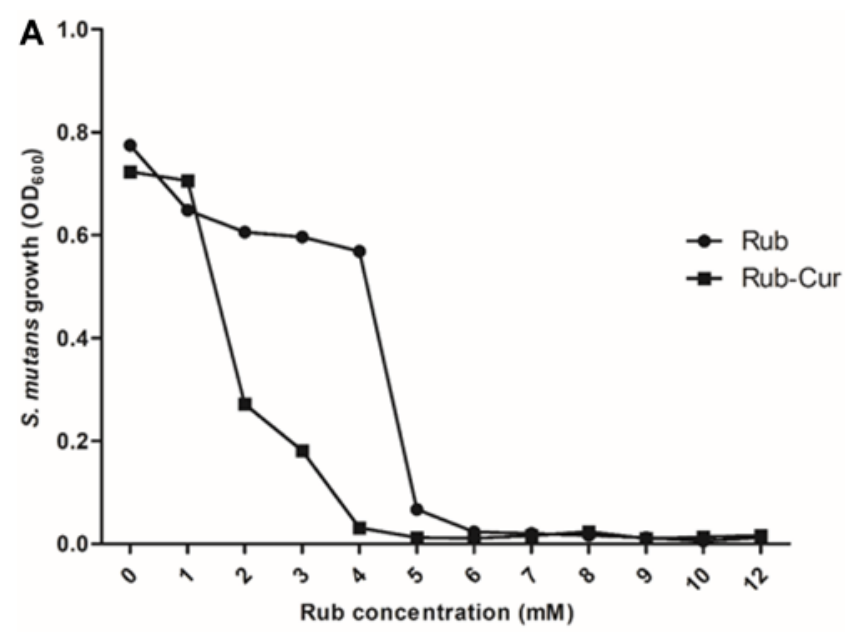

B

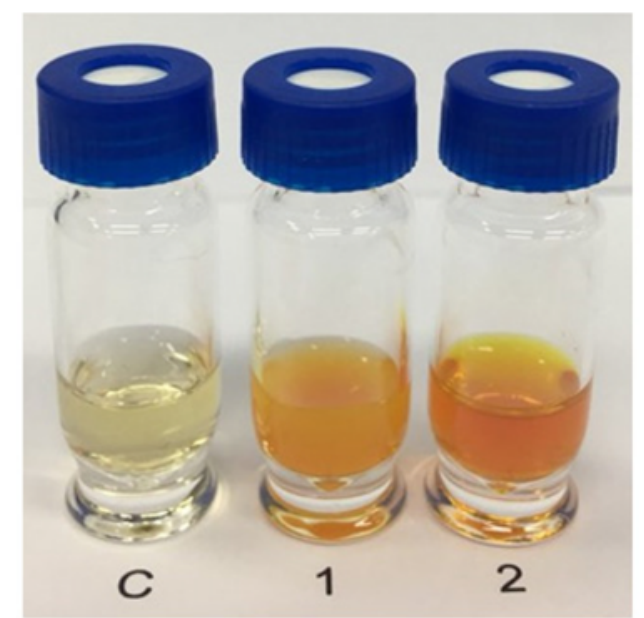

Fig. 3. Growth curve of $S$. mutant in $\mathrm{BHI}$ medium containing $\mathrm{Ru} /$ or Ru-CUR (A) and solubilization of curcumin in DMSO and CUR-Ru complex in BHI medium (B). C, BHI medium; 1, CURDMSO in BHI medium; 2, CUR-Ru in BHI medium.

metabolized only very slowly or not at all by S. mutans [10].

$\mathrm{Ru}$ is well-known as a solubilizer for insoluble compounds $[9,21]$. Curcumin is a compound that has low solubility in water (Zhang et al. 2017). The MIC value of curcumin has been reported against $S$. mutans [22,23]. When trying to measure the MIC of curcumin against $S$. mutans, we faced difficulty in interpreting our results, possibly because of the insoluble and colored precipitant caused by its insolubility in aqueous phase and formation of a colored precipitate (Fig. 3B). Thus, curcumin was prepared to be soluble in water with a $\mathrm{Ru}$ solution. The MIC value of curcumin could not be found, because of its precipitation in solution. CUR-Ru complex with $0.9 \mathrm{mM}$ curcumin and $5 \mathrm{mM} \mathrm{Ru}$ was used for both MIC and MBC measurement (Fig. 3A). By combining curcumin with $\mathrm{Ru}$, the MIC value of $\mathrm{Ru}$ against $S$. mutans decreased from $6 \mathrm{mM}$ by itself to $5 \mathrm{mM}$ in the complex, and the MBC value of Ru decreased from
$8 \mathrm{mM}$ by itself to $5 \mathrm{mM}$ in the complex. Such lower MIC and MBC values of the Ru-CUR complex compared to those of $\mathrm{Ru}$ by itself were due to the synergism between $\mathrm{Ru}$ and curcumin. This result suggests that $\mathrm{Ru}$ can inhibit S. mutans as a bacteriostatic agent, whereas the Ru-CUR complex can inhibit $S$. mutans.

\section{Conclusion}

Rubusoside ( $\mathrm{Ru}, 13-\mathrm{O}-\beta$-glucosyl-19-O- $\beta$-d-glucosyl-steviol), a natural sweetener obtained from leaves of $R$. suavissmimus S. Lee (Rosaceae), showed competitive inhibition against mutansucrase, with $\mathrm{IC}_{50}$ of $2.3 \mathrm{mM}$ and a $K_{i}$ value of $1.1 \pm$ $0.2 \mathrm{mM}$. Such inhibition was through hydrophobic and hydrogen bonding interactions between amino-acid residues in the active site pocket of mutansucrase and $\mathrm{Ru}$. $\mathrm{Ru}$ also inhibited $S$. mutans growth as a bacteriostatic agent. In addition, Ru-CUR showed synergy against $S$. mutans. With these features, $\mathrm{Ru}$ could well be applied as an anti-cariogenic material and a natural sweetener with low calories.

\section{Acknowledgements}

This work was partially supported by the OTTOGI Corporation through the Research and Publication Project, by the Korean Institute of Planning and Evaluation for Technology in Food, Agriculture, Forestry, and Fisheries (IPET) through the Agriculture, Food and Rural Affairs Research Center Support Program, funded by the Ministry of Agriculture, Food, and Rural Affairs (MAFRA) (D. Kim, 710012-03-1-HD220), and by the Korean Institute of Planning and Evaluation for Technology in Food, Agriculture, Forestry, and Fisheries (IPET) through the High Value-added Food Technology Development Program (116013032HD020) funded by the Ministry of Agriculture, Food, and Rural Affairs, Republic of Korea. The present study has been also conducted under Indo-Korea joint research program of Department of Science and Technology, Government of India (Sanction order \# INT/Korea/P-37, June 15, 2017) and under the framework of International Cooperation Program managed (2016K1A3A1A19945059), and by the Basic Science Research Program (2018R1D1A1B07049569, T.T.H. Nguyen, 2018R1C1B6006348, I. Mok, 2018R1D1A1A09083366, D. Kim) managed by the NRF, Republic of Korea.

Electronic Supplementary Material (ESM) The online version of this article (doi: 10.1007/s12257-018-0408-0) contains supplementary material, which is available to authorized users. 


\section{References}

1. van Houte, J. (1994) Role of micro-organisms in caries etiology. J. Dent. Res. 73: 672-681.2.

2. Schilling, K. M. and W. H. Bowen (1992) Glucans synthesized in situ in experimental salivary pellicle function as specific binding sites for Streptococcus mutans. Infect. Immun. 60: 284-295.

3. Lee, D., Y. Seo, M. S. Khan, J. Hwang, Y. Jo, J. Son, K. Lee, C. Park, S. Chavan, A. A. Gilad, and J. Choi (2018) Use of nanoscale materials for effective prevention and extermination of bacterial biofilms. Biotechnol. Boproc. Eng. 23: 1-10.

4. Monchois, V., R. M. Willemot, and P. Monsan (1999) Glucansucrases: mechanism of action and structure-function relationships. FEMS Microbiol. Rev. 23: 131-151.

5. Tamesada, M., S. Kawabata, T. Fujiwara, and S. Hamada (2004) Synergistic effects of streptococcal glucosyltransferases on adhesive biofilm formation. J. Dent. Res. 83: 874-879.

6. Ito, K., S. Ito, T. Shimamura, S. Weyand, Y. Kawarasaki, T. Misaka, K. Abe, T. Kobayashi, A. D. Cameron, and S. Iwata (2011) Crystal structure of glucansucrase from the dental caries pathogen Streptococcus mutans. J. Mol. Biol. 408: 177-186.

7. Xu, X., X. D. Zhou, and C. D. Wu (2011) The tea catechin epigallocatechin gallate suppresses cariogenic virulence factors of Streptococcus mutans. Antimicrob. Agents Chemother. 55: 1229-1236.

8. Zhang, M., T. Dai, and N. Feng (2017) A novel solubilityenhanced rubusoside-based micelles for increased cancer therapy. Nanoscale Res. Lett. 12: 274.

9. Nguyen, T. T. H., S. J. Jung, H. K. Kang, Y. M. Kim, Y. H. Moon, M. Kim, and D. Kim (2014) Production of rubusoside from stevioside by using a thermostable lactase from Thermus thermophilus and solubility enhancement of liquiritin and teniposide. Enzyme Microb. Tech. 64-65: 38-43.

10. Chu, J., T. Zhang, and K. He (2016) Cariogenicity features of Streptococcus mutans in presence of rubusoside. BMC Oral Health. 16: 54.

11. Lim, H. J., T. T. H. Nguyen, N. M. Kim, J. S. Park, T. S. Jang, and D. Kim (2017) Inhibitory effect of flavonoids against NS2B-NS3 protease of ZIKA virus and their structure activity relationship. Biotechnol. Lett. 39: 415-421.

12. Yu, S. H., S. H. Kwak, T. T. H. Nguyen, Y. S. Seo, C. Song, I. K. Mok, and D. Kim (2018) Decrease of insoluble glucan formation in Streptococcus mutans by co-cultivation with Enterococcus faecium T7 and glucanase addition. Biotechnol. Lett. 40: 375-381.
13. Kim, D. H., J. C. Park, G. E. Jeon, C. S. Kim, and J. H. Seo (2017) Effect of the size and shape of silver nanoparticles on bacterial growth and metabolism by monitoring optical density and fluorescence intensity. Biotechnol. Bioproc. Eng. 22: 210-217.

14. Hong, S. J., J. H. Lee, E. J. Kim, H. J. Yang, Y. K. Chang, J. S. Park, and S. K. Hong (2017) In vitro and in vivo investigation for biological activities of neoagarooligosaccharides prepared by hydrolyzing agar with beta-agarase. Biotechnol. Bioproc. Eng. 22: 489-496.

15. Nguyen, T. T. H., N. Kim, S. C. Yeom, S. Han, S. H. Kwak, S. B. Kim, J. S. Park, I. K. Mok, and D. Kim (2017) Biological characterization of epigallocatechin gallate complex with different steviol glucosides. Biotechnol. Bioproc. Eng. 22: 512517.

16. Nguyen, T. T., H. J. Woo, H. K. Kang, V. D. Nguyen, Y. M. Kim, D. W. Kim, S. A. Ahn, Y. Xia, and D. Kim (2012) Flavonoidmediated inhibition of SARS coronavirus 3C-like protease expressed in Pichia pastoris. Biotechnol. Lett. 34: 831-838.

17. Song, J., B. Choi, E. J. Jin, Y. Yoon, and K. H. Choi (2012) Curcumin suppresses Streptococcus mutans adherence to human tooth surfaces and extracellular matrix proteins. Eur. J. Clin. Microbiol. 31: 1347-1352.

18. Mukasa, H., H. Tsumori, and A. Shimamura (1985) Isolation and characterization of an extracellular glucosyltransferase synthesizing insoluble glucan from Streptococcus mutans serotype c. Infect. Immun. 49: 790-796.

19. Shimamura, A., H. Tsumori, and H. Mukasa (1982) Purification and properties of Streptococcus mutans extracellular glucosyltransferase. Biochim. Biophys. Acta. 702: 72-80.

20. Pankey, G. A., and L. D. Sabath (2004) Clinical relevance of bacteriostatic versus bactericidal mechanisms of action in the treatment of Gram-positive bacterial infections. Clin. Infect. Dis. 38: 864-870.

21. Zhang, F., G. Y. Koh, D. P. Jeansonne, J. Hollingsworth, P. S. Russo, G. Vicente, R. W. Stout, and Z. J. Liu (2011) A novel solubility-enhanced curcumin formulation showing stability and maintenance of anticancer activity. J. Pharm. Sci. 100: 27782789.

22. Hu, P., P. Huang, and M. W. Chen (2013) Curcumin reduces Streptococcus mutans biofilm formation by inhibiting sortase A activity. Arch. Oral Biol. 58: 1343-1348.

23. Song, J., B. Choi, E. J. Jin, Y. Yoon, and K. H. Choi (2012) Curcumin suppresses Streptococcus mutans adherence to human tooth surfaces and extracellular matrix proteins. Eur. J. Clin. Microbiol. Infect. Dis. 31: 1347-1352.

Publisher's Note Springer Nature remains neutral with regard to jurisdictional claims in published maps and institutional affiliations. 